\title{
C-MRS Meets in Beijing
}

The week of June 17, 1990 saw the Chinese Materials Research Society (C-MRS) holding its first International Advanced Materials Meeting in Beijing, China. Fourteen separate parallel symposia, analogous to those found at most MRS meetings, covered a multiplicity of materials research topics. Each symposium was limited to about 60 participants to enhance opportunities for individual exchanges and to best fit the meeting's accommodations. On three successive mornings, a plenary symposium (Symposium N) was the sole session. Plenary talks by 14 invited distinguished materials scholars provided overviews on a wide variety of research areas and contributed strongly to the meeting's multidisciplinary character. Of the 800 participants, about 114 were from 20 foreign countries.

The meeting's venue, the Jing Feng Hotel, is located in the southwest part of Beijing some distance from the city's center. This somewhat sequestered environment provided an opportunity for participants to interact more intimately throughout the week. Nearly all the participants stayed at the conference hotel, where the sessions were held. All meeting logistics, from the attendees' arrival to their departure, from program planning to constructing poster boards, were handled by conference volunteers.

In addition to the technical sessions, the C-MRS meeting offered several social opportunities-a beer party the evening of June 18, a reception the evening of June 19, and a banquet the evening of June 21 . The banquet filled the largest restaurant/ ballroom of the Beijing Hotel in downtown Beijing. The meeting chairs also created opportunities to acknowledge contributions to the meeting's organization by members of the International Advisory Committee and by several symposium chairs.

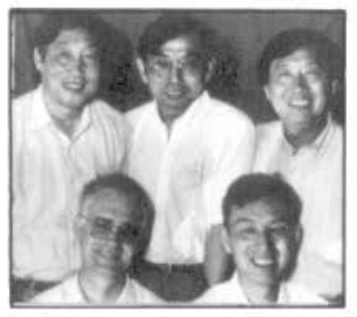

Symposium G chairs: (top, L-R) Guoliang Chen, Donglian Lin, C.T. Liu; (bottom, L-R) G. Sautoff, Zengyong Zhong.
One evening, an acrobatics troupe performed for participants and their guests in an auditorium adjoining the conference hotel grounds.

C-MRS, a conglomerate of some 30 societies, had meetings in 1986 and 1988, although not international ones. The success of those meetings, however, led to this first international meeting. This year's meeting was endorsed by cooperating societies from Japan (AMSES), Europe (E-MRS), and the United States (MRS). Submitted papers numbered 623, most presented in oral sessions and 163 as posters. Accepted papers will appear in several proceedings volumes to be published by the Elsevier North-Holland Publishing Company (Amsterdam).

In the opening plenary session, Guangshao Zhou, president of the Academia Sinica of Beijing, addressed attendees. This reflected the importance of the $C$. MRS meeting to the scientific and academic community in China. In addition, the ceremonial part of the June 21 banquet got brief coverage on Chinese television's evening news.

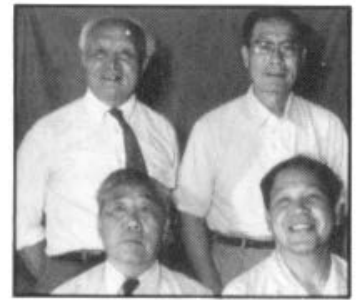

Symposium A chairs:

(top, L-R) Changxu Shi,

Dongsheng Yan; (bottom,

L-R) Hengde Li, Zizhao Gan;

Zhongxian Zhao is not shown.

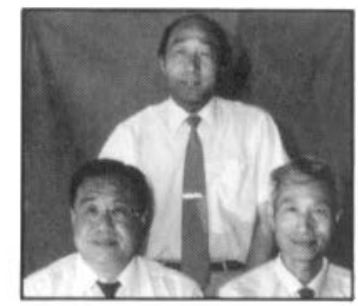

Symposium B chairs: (top) Chenggong Li; (bottom, $L-R)$ Renjie Wu, Benlian Zhou; E. Fitzer is not shown.

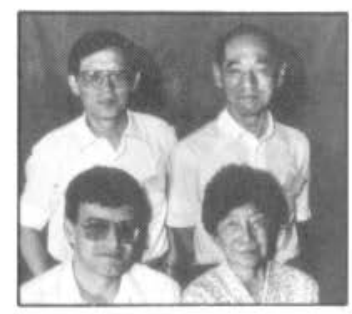

Symposium I chairs: (top, L-R) Lishi Wen, Akira Kinbara; (bottom, L-R) Avishay Katz, Lin Li.

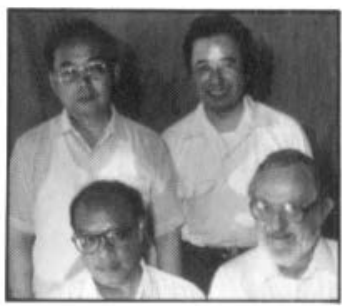

Symposium C chairs: (top, L-R) Qiming Yuan, Xi Yao; (bottom, L-R) Jingkun Guo, I. Eric Cross.

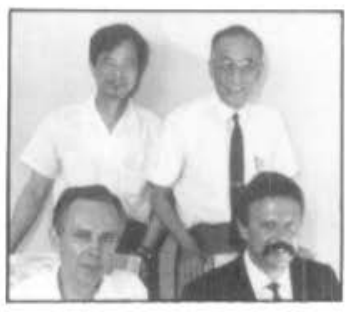

Symposium / chairs: (top, L-R) Zhongguang Wang, Minggao Yan; (bottom, L-R) Y.I. Ragozin, R.O. Ritchie. 


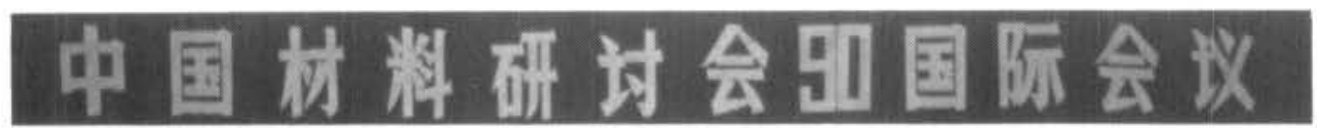

be introduced in a "somewhat market" way, also announcing that institutes would be open to participation from all areas of China. He noted that funding for applications and products would increase, but that a percentage would be protected for basic research. Open laboratories with more visiting scientists than permanent staff would be forthcoming and the engineering sciences would be strengthened and encouraged to transfer technology to industry. Zhou even forecast that the Academy itself would serve as an incubator and provide loans or start-up capital for technology-based industries.

Some notable technical presentations can be mentioned. In Symposium A on superconductivity, $\mathrm{Xu}$ Qinlun (University of Science \& Technology, Hefei, China) pre-

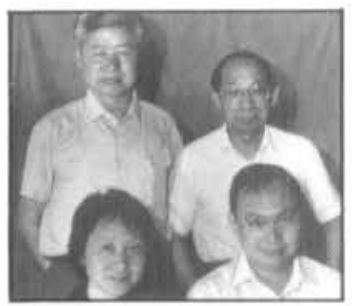

Symposium D chairs: (top, L-R) Minhua liang, Fuxi Gan; (bottom, L-R) Meiying Kong, C.W. Tu.

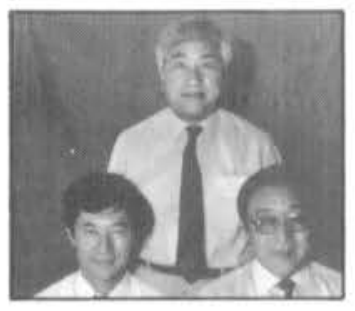

Symposium K chairs: (top) Shizhuo Li; (bottom, L-R) Koji Kato, Jiajun Liu. sented a report on a $130 \mathrm{~K}$ high-temperature superconductor. The system's composition, a bismuth, lead, antimony, strontium, calcium, copper-oxide mixed phase, resulted in rather convincing experimental data. The proposed underlying physical reason for a high transition temperature, compared to the highest bismuth-system temperature discovered so far $(110 \mathrm{~K})$, was somewhat less convincing. A presentation by the well-known $R$. Hasiguti of Japan (Symposium N) dealt with the relevance of lattice defects to reported observations on cold fusion. Hasiguti contended that the energy needed for deuterons to react at a rate comparable to the lowest-intensity positive result reported on cold fusion could be obtained by assuming the presence of lattice defects in palladium metal electrodes. The defects would trap multiple deuterium atoms and provide adequate accelerations.

By most measures, the C-MRS meeting was quite successful, reaping many congratulatory remarks. "Everybody was mostly seduced by the high quality of the scientific discussions but also [by] the wealth of

human contacts," commented P. Hagenmuller (France). And according to J.E.E. Baglin (U.S.A.), "both the organization and content of the conference were excellent, foreign visitors were made very comfortable,... [and] the diversity of symposium topics was a strong expression of the breadth of representation of multiple disciplines within the materials community in China."

\begin{tabular}{|c|c|}
\hline \multicolumn{2}{|r|}{ C-MRS Meeting } \\
\hline $\begin{array}{l}\text { Sympo- } \\
\text { sium }\end{array}$ & Topic \\
\hline A & High $T_{c}$ Superconductors \\
\hline B & $\begin{array}{l}\text { Advanced Composite } \\
\text { Materials }\end{array}$ \\
\hline C & $\begin{array}{l}\text { High-Performance } \\
\text { Ceramics }\end{array}$ \\
\hline D & Optoelectronic Materials \\
\hline $\mathrm{E}$ & $\begin{array}{l}\text { Advanced Engineering } \\
\text { Plastics }\end{array}$ \\
\hline F & $\begin{array}{l}\text { Functional Polymer } \\
\text { Materials }\end{array}$ \\
\hline G & $\begin{array}{l}\text { Intermetallic Compounds } \\
\text { and High-Temperature } \\
\text { Materials }\end{array}$ \\
\hline $\mathrm{H}$ & $\begin{array}{l}\text { Laser and Particle Beam } \\
\text { Interactions with Solids }\end{array}$ \\
\hline I & Thin Films \\
\hline J & $\begin{array}{l}\text { Fatigue and Fracture } \\
\text { Behavior in Materials }\end{array}$ \\
\hline K & $\begin{array}{l}\text { Recent Advances of } \\
\text { Tribomaterials }\end{array}$ \\
\hline L & Biomedical Materials \\
\hline M & $\begin{array}{l}\text { Microstructures and } \\
\text { Materials Design }\end{array}$ \\
\hline $\mathrm{N}$ & $\begin{array}{l}\text { Frontiers of Materials } \\
\text { Research }\end{array}$ \\
\hline
\end{tabular}

Symposium E chairs: Mengxian Ding; (bottom, L-R) L.A. Utracki, Xi Xu.

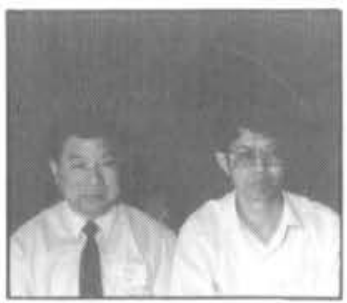

Symposium L chairs: (L-R) Han Zou, Tingfei Xe; Y. Ikada is not shown.

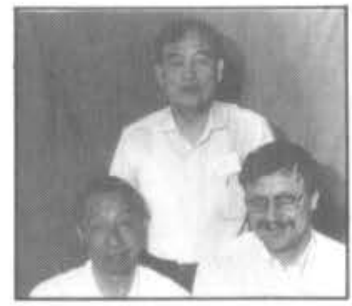

Symposium F chairs: (top) Fosong Wang; (bottom L-R) Renyluan Qian, E.M. Genies; Tisato Kajiyama is not shoron.

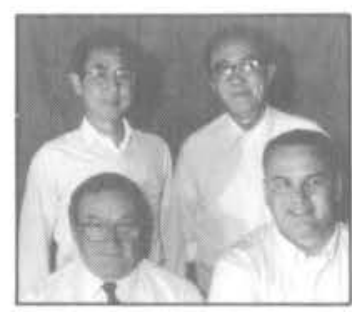

Symposium M chairs: (top, L-R) Jiajun Xiong, Jimei Xiao; (bottom, L-R) John Radavich, John D. Dow.

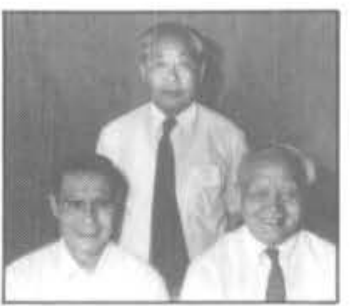

Symposium N chairs: (top) Hengde Li, also secretary general for the C-MRS Meeting: (bottom, L-R) Dongsheng Yan and Changxu Shi, also chairs for the C-MRS Meeting. 